\title{
Comportamento de pastejo e ingestão de forragem por novilhas de corte em pastagens de milheto e papuã
}

\author{
Vagner Guasso da Costa ${ }^{1}$, Marta Gomes da Rocha ${ }^{2}$, Luciana Pötter ${ }^{2}$, Dalton Roso ${ }^{1}$, Aline \\ Tatiane Nunes da Rosa ${ }^{1}$, Jonatas dos Reis ${ }^{3}$
}

\footnotetext{
1 Programa de Pós-graduação em Zootecnia Universidade Federal de Santa Maria, RS.

2 Departamento de Zootecnia, UFSM, Santa Maria, RS, Brasil, 97105-900.

${ }^{3}$ Graduação em Zootecnia, Centro de Ciências Rurais - UFSM.
}

RESUMO - Foram estudados o desempenho, o comportamento e a ingestão de forragem por novilhas de corte em pastagem de milheto (Pennisetum americanum (L.) Leeke) e papuã (Urochloa plantaginea) no período de janeiro a abril de 2008 . Foi utilizado o método de pastejo contínuo com número variável de animais. A ingestão de forragem foi estimada nos estádios vegetativo e reprodutivo das forrageiras usando o óxido de cromo como indicador da produção fecal. As avaliações de comportamento foram feitas por meio de observação visual, em quatro períodos contínuos de 24 horas. Os valores médios de massa de forragem, oferta de forragem e oferta de lâminas foliares foram de $3.927 \mathrm{~kg} / \mathrm{ha}$ de MS, $14,6 \mathrm{~kg}$ de MS/100 kg de peso corporal (PC) e $3,36 \mathrm{~kg}$ de $\mathrm{MS} / 100 \mathrm{~kg}$ de $\mathrm{PC}$, respectivamente. As variáveis do pasto, o desempenho animal, o comportamento ingestivo e a ingestão de forragem foram semelhantes entre milheto e papuã. As variáveis da forragem, desempenho animal e tempos de pastejo, ócio e ruminação e número de bocados por dia apresentaram variação ao longo dos dias de utilização da pastagem. A ingestão de forragem foi de $2,49 \%$ do peso corporal e não variou conforme o estádio fenológico. Em áreas infestadas com papuã, sua utilização em pastejo proporciona desempenho semelhante ao obtido com milheto.

Palavras-chave: massa de bocado, óxido de cromo, Pennisetum americanum, taxa de bocados, tempo de pastejo, Urochloa plantaginea

\section{Grazing behavior and forage ingestion by beef heifers on pearl millet and alexander grass pastures}

\begin{abstract}
It was studied performance, behavior and forage ingestion by beef heifers on pearl millet (Pennisetum americanum (L.) Leeke) and Alexander grass (Urochloa plantagínea) pastures from January to April 2008. The continuous grazing method with a variable number of animals was used. Forage ingestion was estimated during vegetative and reproductive stage of forage plants using chromic oxide as fecal production marker. Evaluations of behavior were carried out by visual observation in four 24-hour continuous periods. Mean values of forage mass, forage offer and leaf blade offer were 3,927 kg/ha of $\mathrm{DM}, 14.6 \mathrm{~kg}$ of DM/100 kg BW and $3.36 \mathrm{~kg}$ of DM/100 kg BW, respectively. The variables of the pasture, animal performance, ingestive behavior and forage intake were similar for pearl millet and alexander grass. Variables of forage, animal performance and grazing times, idle and rumination and number of bites per day showed variation over days of pasture utilization. Forage ingestion was $2.49 \%$ of the body weight and it did not vary according to phenological stage. Use of sites infested with alexander grass as pastures provides performance similar to the one obtained with pearl millet.
\end{abstract}

Key Words: bite mass, bite rate, chromic oxide, grazing time, Pennisetum americanum, Urochloa plantaginea

\section{Introdução}

As pastagens anuais cultivadas no verão têm sido difundidas no Rio Grande do Sul, em decorrência de sua alta produção de pasto, por propiciarem elevados ganhos individuais aliados a alta taxa de lotação e retorno econômico satisfatório (Montagner et al., 2008). Entre as gramíneas anuais de verão, o milheto (Pennisetum americanum (L.) Leeke) é a espécie mais difundida para pastejo.
O crescimento das áreas com lavouras de verão, principalmente soja e milho, no Rio Grande do Sul aumentou as áreas infestadas com papuã (Urochloa plantaginea (L.) Hitchc). A grande produção de sementes dessa espécie e sua persistência no solo por vários anos fazem com que ela seja reconhecida como a invasora mais importante dessas culturas. O pastejo devidamente manipulado pode constituir ferramenta econômica e ecológica para redução da população de gramíneas invasoras, reduzindo o uso de 
insumos, ou seja, torna-se opção de baixo impacto ambiental. O papuã foi previamente avaliado sob pastejo (Martins et al., 2000) e há indícios de que tenha potencial para utilização no sistema pecuário. Se for comprovado o seu potencial, essa espécie pode compor sistemas de integração lavourapecuária, pois apresenta baixo custo para rotação com lavouras de grãos no período de inverno.

Para avaliar forrageiras sob pastejo, além da simples comparação do desempenho obtido, é necessário mensurar as diferenças físicas e químicas entre as espécies avaliadas e essas características, conforme relatos de Genro et al. (2004), refletem em alterações no comportamento ingestivo e ingestão de forragem. Então, é importante avaliar a ingestão de forragem aliada ao comportamento ingestivo para que sejam mais bem compreendidas as relações que definem o desempenho animal. De posse dessas informações, seria possível conciliar com informações de produtividade vegetal e escolher com mais segurança as espécies para uso sob pastejo.

Quando forrageiras são avaliadas em pastejo, entre as características a serem medidas está a estrutura do dossel, que pode ser descrita por variáveis como altura, massa de folhas e relação folha/colmo, as quais indicam as condições potenciais para os animais exercerem a seleção, colherem a forragem e produzirem.

Este trabalho foi conduzido com o objetivo de relacionar características estruturais e químicas do pasto e de desempenho animal com o comportamento ingestivo e a ingestão de forragem por novilhas de corte em pastejo contínuo sobre milheto e papuã.

\section{Material e Métodos}

O experimento foi desenvolvido em área do Departamento de Zootecnia da Universidade Federal de Santa Maria, situada na Depressão Central do Rio Grande do Sul. O clima da região é subtropical úmido, conforme classificação de Köppen. O solo é classificado como Argissolo Vermelho distrófico arênico, integrante da unidade de mapeamento São Pedro (Embrapa, 2006) e, conforme os resultados da análise, possuía as seguintes características: $\mathrm{pH}-\mathrm{H} 2 \mathrm{O}=5,0$; índice $\mathrm{SMP}=5,8 ; \%$ argila $=$ $19,2 \mathrm{~m} / \mathrm{V} ; \mathrm{P}=13,4 \mathrm{mg} / \mathrm{L} ; \mathrm{K}=92 \mathrm{mg} / \mathrm{L} ; \% \mathrm{MO}=2,7 \mathrm{~m} / \mathrm{V}$; $\mathrm{Al}=0,2 \mathrm{cmolc} / \mathrm{L} ; \mathrm{Ca}=4,6 \mathrm{cmolc} / \mathrm{L} ; \mathrm{Mg}=2,2 \mathrm{cmolc} / \mathrm{L}$; saturação de bases $=56,6 \%$; e saturação por $\mathrm{Al}=3 \%$.

A área experimental foi constituída de oito piquetes de 0,8 ha, considerados unidades experimentais e mais uma área contígua de 1,5 ha. A pastagem de milheto (Pennisetum americanum (L.) Leeke) foi implantada por semeadura convencional, com subsolagem, gradagem de revolvimento e mais uma gradagem de nivelamento. A semeadura foi realizada em linha, em 20/11/2008, utilizando-se $30 \mathrm{~kg} / \mathrm{ha}$ de sementes. Posteriormente, foram realizadas uma gradagem de nivelamento e uma compactação com rolo. Para a pastagem de papuã (Urochloa plantagínea), foi utilizado o banco de sementes da área e realizada subsolagem, gradagem de nivelamento e uma compactação com rolo. A adubação consistiu de $250 \mathrm{~kg} / \mathrm{ha}$ da fórmula 05-20-20 (NPK) e, em cobertura, foram adicionados $67 \mathrm{~kg} / \mathrm{ha}$ de nitrogênio, na forma de ureia, em 10/1/2008, 7/2/2008 e 13/3/2008.

O método de pastejo foi o contínuo, com ajuste de carga (Heringer \& Carvalho, 2002) para manter a massa de forragem em $3 \mathrm{t} /$ ha de matéria seca (MS). A utilização das pastagens iniciou em 27/12/2007 e os animais foram adaptados ao local durante oito dias antes do início do período experimental $(5 / 1 / 2008)$.

Foram utilizados quatro animais-teste por repetição: dois deles receberam, via oral, óxido de cromo para determinação da excreção fecal e três foram utilizados para avaliação do comportamento ingestivo. Os animais-teste foram novilhas de corte, mestiças, com predominancia da raça Aberdeen Angus, com idade inicial de 15 meses e peso corporal inicial de 253,6 $\pm 12,4 \mathrm{~kg}$.

A massa de forragem foi avaliada a cada 14 dias, pela técnica visual com dupla amostragem, com 20 estimativas visuais e cinco cortes. $\mathrm{Na}$ mesma ocasião, foi medida a altura do dossel, com régua de plástico rígido, nos mesmos pontos utilizados para avaliação da massa de forragem. Os valores de massa de forragem utilizados para correlações com as variáveis de comportamento ingestivo foram provenientes de amostragens feitas logo após as datas das observações de comportamento.

A forragem proveniente dos cortes foi homogeneizada e dividida em duas subamostras, para quantificação do teor de MS do pasto e para separação manual dos componentes botânicos e morfológicos. O teor de MS foi estimado pela secagem das amostras em estufa com circulação forçada de ar a $55^{\circ} \mathrm{C}$ por 72 horas. Após a separação botânica e secagem dos componentes estruturais da pastagem, foi avaliada a participação percentual de lâminas foliares, colmos, inflorescências, material morto e outras espécies e, a partir da proporção de folhas e colmos, foi quantificada a relação folha:colmo.

A taxa de acúmulo de forragem $(\mathrm{kg} / \mathrm{ha} / \mathrm{dia} \mathrm{MS})$ foi avaliada em três gaiolas de exclusão ao pastejo por piquete. A disponibilidade diária de forragem $(\mathrm{kg} / \mathrm{ha} / \mathrm{dia}$ de MS) foi obtida pela soma da taxa de acúmulo com a massa de forragem do período, e o valor obtido foi dividido pelo número de dias deste. 
A oferta de forragem foi expressa como a disponibilidade de forragem dividida pela carga animal, expressa em $\mathrm{kg}$ de MS de forragem por hectare/kg de peso corporal/dia (Sollenberg et al., 2005). A oferta de lâminas foliares verdes foi obtida por meio da multiplicação da oferta de forragem pelo percentual de lâminas foliares na massa de forragem. Por simulação manual de pastejo, foram tomadas amostras de forragem para avaliação da composição químicas do pasto.

A pesagem dos animais foi realizada a cada 28 dias, com jejum prévio de sólidos e líquidos de 12 horas e, nas mesmas datas, foram realizadas as avaliações do escore de condição corporal, variando de 1 (muito magro) a 5 (muito gordo). Para o cálculo de carga animal foi utilizado o somatório do peso médio dos animais-teste, com o peso médio de cada animal regulador multiplicado pelo número de dias que permaneceu no piquete, dividido pelo número de dias totais do período.

A avaliação da ingestão de forragem foi realizada nos estádios vegetativo (15 a 26/1/2008) e reprodutivo (4 a $15 / 3 / 2008)$ dos pastos. Foi utilizado óxido de cromo $\left(\mathrm{Cr}_{2} \mathrm{O}_{3}\right)$ como indicador externo e o período de fornecimento de óxido de cromo foi de 12 dias (seis dias para adaptação e seis dias para coleta fecal). A dosificação foi feita, por via oral, com $10 \mathrm{~g}$ de óxido de cromo divididas em duas doses diárias de mesmo peso, pela manhã (7h30) e à tarde (17h30). O nível de cromo nas fezes secas foi avaliado por espectrofotometria de absorção atômica pela técnica adaptada por Kozlozki et al. (1998). Avaliaram-se a ingestão de MS (IMS, em g/dia) pela fórmula: IMS = produção fecal/ 1- digestibilidade in vitro da matéria seca, e a ingestão de MS, em porcentagem do peso corporal.

Nas amostras de forragem obtidas por meio da simulação manual de pastejo, foram determinados os teores de matéria seca e matéria orgânica (MO), matéria mineral (MM) e nitrogênio, segundo as normas da AOAC (método 984.13, 1995). Os teores de extrato etéreo (EE) foram obtidos por extração com éter etílico, com regulagem da chapa aquecedora a $180^{\circ} \mathrm{C}$ em aparelho extrator tipo Soxleht. Os teores de fibra em detergente neutro (FDN), fibra em detergente ácido (FDA), lignina em detergente ácido (LDA) foram avaliados de acordo com Robertson \& Van Soest (1981), feita com uso de sacos de poliéster, conforme modificação de Komarek (1993). Os teores de nitrogênio insolúvel em detergente neutro (NIDN) e nitrogênio insolúvel em detergente ácido (NIDA) foram analisados de acordo com metodologia descrita por Licitra et al. (1996). O teor de cinzas da FDN foi obtido por calcinação em mufla a $550^{\circ} \mathrm{C}$.

O teor de nutrientes digestíveis totais (NDT) da dieta foi estimado com base na composição química utilizando-se o modelo proposto por NRC (2001): NDT $=\mathrm{CNFdig}+\mathrm{PB} \operatorname{dig}$ $+2,25 \times \mathrm{EE} \operatorname{dig}+\mathrm{FDN} \operatorname{dig}-7$, em que: $\mathrm{CNFdig}=0,98 *(100-$ $\left(\mathrm{FDN}_{\mathrm{cn}}+\mathrm{PB}+\mathrm{EE}+\right.$ Cinzas $\left.)\right) ; \mathrm{PB}$ dig forragem $=\mathrm{PB}^{*} \mathrm{Exp}$ $[-1,2 *(\mathrm{PIDA} / \mathrm{PB})] ; \mathrm{EE} \operatorname{dig}=(\mathrm{EE}-1) ; \mathrm{FDN} \operatorname{dig}=0,75^{*}$ $\left(\mathrm{FDN}_{\mathrm{cn}}-\mathrm{LDA}\right) *\left[1-\left(\mathrm{LDA} / \mathrm{FDN}_{\mathrm{cn}}\right)^{0,667}\right]$ e CNFdig $=$ carboidratos não-fibrosos digestíveis; PBdig forragem = proteína bruta digestível da forragem; EEdig = extrato etéreo digestível; FDNdig = fibra em detergente neutro digestível; LDA = lignina; PIDA = proteína insolúvel em detergente ácido; $\mathrm{FDN}_{\mathrm{cn}}=$ fibra em detergente neutro livre de cinzas.

As medidas de tempo de pastejo, ruminação e outras atividades foram feitas nas datas de $31 / 1$ e $26 / 2$ (estádio vegetativo) e 28/3 e 22/4 (estádio reprodutivo), por observação visual direta durante 24 horas. Foram feitos registros da atividade de maior ocorrência ao final do intervalo de dez minutos (Jamieson \& Hodgson, 1979a), anotando-se as atividades de pastejo, ruminação e ócio. O tempo gasto pelos animais na seleção e apreensão da forragem, incluindo os espaços de tempo utilizados no deslocamento para a seleção da dieta, foi considerado tempo de pastejo. O tempo de ruminação foi identificado como a cessação do pastejo e a realização da atividade de mastigação sem busca e apreensão de forragem. Tempo de ócio foi considerado o tempo em que o animal mantinha-se em descanso (Forbes, 1988) e as atividades registradas em tempo total por dia (minutos/dia).

Concomitantemente às observações da atividade de pastejo, foram registrados, durante a manhã e tarde, o número máximo possível de registros, com cronômetro, do tempo necessário para os animais realizarem 20 bocados (Hodgson, 1982) para cálculo da taxa de bocados (bocados/ minuto). O número de bocados diários (bocados/dia) foi obtido pela multiplicação da taxa de bocados pelo tempo diário de pastejo (minutos/dia).

Os valores de massa de bocado (g MO/boc) foram estimados pela equação adaptada de Allden \& Whittaker (1970): $\mathrm{MB}=\mathrm{I} /(\mathrm{NB} \times \mathrm{TP})) * \% \mathrm{MO}$, em que: $\mathrm{MB}=$ massa do bocado (g MO); I = ingestão de MS $\left(\mathrm{g} \cdot \mathrm{dia}^{-1}\right) ; \mathrm{NB}=$ taxa de bocados (boc./min); TP = tempo de pastejo ( $\mathrm{min} . / \mathrm{dia})$; $\% \mathrm{MO}=$ teor de matéria orgânica da forragem aparentemente consumida pelos animais em pastejo.

O delineamento experimental foi o inteiramente casualizado, com medidas repetidas no tempo, com dois tratamentos, três repetições de área para milheto e cinco para papuã. A comparação entre tratamentos e períodos de utilização da pastagem foi realizada por meio de análise de variância. As análises foram efetuadas com o auxílio do programa estatístico SAS, de acordo com o seguinte modelo matemático geral: 


$$
\gamma_{\mathrm{ijk}}=\mu+\tau_{\mathrm{i}}+\lambda_{(\mathrm{i}) \mathrm{k}}+\alpha_{\mathrm{j}}+(\tau \alpha)_{\mathrm{ij}}+\varepsilon_{\mathrm{ijk}}
$$
em que: $\gamma_{\mathrm{ijk}}=$ variáveis dependentes; $\mu=$ média de todas as observações; $\tau_{\mathrm{i}}=$ efeito do i-ésimo tratamento; $\alpha_{\mathrm{j}}=$ efeito do j-ésimo período; $(\tau \alpha)_{\mathrm{ij}}=$ interação entre o tratamento e o j-ésimo período; $\lambda_{(\mathrm{i}) \mathrm{k}}=$ efeito da k-ésima repetição dentro do i-ésimo tratamento; $\varepsilon_{\mathrm{ijk}}=$ erro experimental residual.

Foi realizado teste de correlação e comparação de médias a 5\% de significância. Os dados foram submetidos também à análise de regressão considerando os dias de utilização da pastagem. Na análise de regressão, a escolha dos modelos baseou-se na significância dos coeficientes linear, quadrático e cúbico, utilizando-se o teste "t", de Student, a $5 \%$ de probabilidade. Para identificar as variáveis independentes com influência sobre a ingestão de matéria seca e o ganho médio diário, foi utilizado o método Stepwise. Foram obtidas todas as equações possíveis, e uma foi selecionada de acordo com os seguintes critérios: menor valor-P, menor variância residual, maior coeficiente de determinação e menor número de variáveis independentes. Como ferramenta de auxílio às análises estatísticas, foi utilizado o procedimento GLM (SAS, 2001).

\section{Resultados e Discussão}

Os dados meteorológicos referentes ao período experimental e às datas de avaliação do comportamento ingestivo (Tabela 1) comprovam que as médias mensais de temperatura foram condizentes com as médias históricas. A temperatura média do primeiro dia de avaliação foi a única inferior à temperatura média do mês, e o mês de janeiro foi o mais quente no decorrer do experimento.

As temperaturas médias dos demais dias de avaliação foram, em média, $10 \%$ superiores à temperatura média dos respectivos meses e as máximas ocorridas nos dias de avaliação foram maiores que a média diária mensal. A precipitação ocorrida durante os últimos meses do experimento foi menor que as médias históricas, mas não foram observados sinais de déficit hídrico.

Não houve interação tratamento $\times$ período $(\mathrm{P}>0,05)$ para massa de forragem, taxa de acúmulo de forragem e altura do dossel. Essas variáveis não diferiram entre as espécies $(\mathrm{P}>0,05)$. Os valores médios para massa de forragem, taxa de acúmulo e altura do dossel foram, respectivamente, de 3,9 t/ha de MS, 160,9 kg/ha/dia e 20,2 cm. Os valores observados de massa de forragem foram superiores aos relatados em outros trabalhos com papuã e milheto (Martins et al., 2000; Montagner et al., 2008) e os resultados estão relacionados à maior taxa de acúmulo de forragem verificada neste trabalho.

A altura do dossel foi influenciada pelos dias de utilização da pastagem e teve ajuste ao modelo linear de regressão $\left(\hat{Y}=31,63-0,17\right.$ dias; $r^{2}=52,0 \% ; C V=24,5 \%$; $\mathrm{P}<0,0001$ ), variando de 26,5 a $12,5 \mathrm{~cm}$, respectivamente, do início até o final da utilização da pastagem, equivalente a uma redução de $52,7 \%$.

A taxa de acúmulo de forragem não foi afetada pelos dias de utilização $(\mathrm{P}>0,05)$ e o valor obtido no último período, $154,2 \mathrm{~kg} / \mathrm{ha}$ de MS, correspondeu a 79,6\% do valor do primeiro período de avaliação. A produção total de MS, média de $16.405,6 \mathrm{~kg} / \mathrm{ha}$ de $\mathrm{MS}$, não diferiu $(\mathrm{P}>0,05)$ entre espécies e pode ser considerada condizente com as produções de milheto adubado com 150 e $300 \mathrm{~kg} / \mathrm{ha}$ de nitrogênio (Heringer \& Moojen, 2002) e superior à produção de papuã, com 200 kg/ha de nitrogênio (Martins et al., 2000).

A oferta de forragem, a oferta de lâminas foliares e a relação folha/colmo não foram afetadas pela combinações entre espécies e o período de avaliação nem diferiram entre espécies ( $\mathrm{P}>0,05$; Tabela 2 ). A oferta de forragem média foi de $14,2 \mathrm{~kg}$ de MS/100 kg de peso corporal (Tabela 2) e corresponde a 6,3 vezes a ingestão estimada pelo National Research Council (NRC, 1996) para novilhas de 18 meses de idade, que é de $2,3 \%$ do peso corporal. A oferta de forragem não variou $(\mathrm{P}>0,05)$ com os dias de utilização da pastagem.

Tabela 1- Dados meteorológicos no decorrer do período exeperimental

\begin{tabular}{|c|c|c|c|c|}
\hline & $31 / 1 / 2008$ & $26 / 2 / 2008$ & $28 / 3 / 2008$ & $22 / 4 / 2008$ \\
\hline Temperatura máxima $\left({ }^{\circ} \mathrm{C}\right)$ & 25,8 & 33,2 & 34,4 & 26,4 \\
\hline Temperatura mínima $\left({ }^{\circ} \mathrm{C}\right)$ & 19,0 & 20,8 & 19,0 & 17,3 \\
\hline Temperatura média $\left({ }^{\circ} \mathrm{C}\right)$ & 22,4 & 27,0 & 26,7 & 21,9 \\
\hline Umidade relativa do ar $(\%)$ & 81,0 & 68,3 & 71,8 & 81,3 \\
\hline \multirow[t]{2}{*}{ Velocidade do vento diária $(\mathrm{km} / \mathrm{hora})^{1}$} & 17,9 & 14,8 & 6,7 & 5,6 \\
\hline & Janeiro & Fevereiro & Março & Abril \\
\hline Precipitação pluviométrica (mm) & 206,2 & 127,6 & 107,6 & 95,7 \\
\hline Temperatura média $\left({ }^{\circ} \mathrm{C}\right)$ & 24,7 & 24,6 & 23,8 & 20,2 \\
\hline Precipitação pluviométrica $(\mathrm{mm})^{1}$ & 145,1 & 130,2 & 151,7 & 134,7 \\
\hline Temperatura média $\left({ }^{\circ} \mathrm{C}\right)^{1}$ & 24,6 & 24 & 22,2 & 18 \\
\hline
\end{tabular}

${ }^{1}$ Médias históricas, de 1961 a 2008, relativas a todo o mês (Estação meteorológica da Universidade Federal de Santa Maria). 
Tabela 2 - Valores médios da oferta de forragem, oferta de lâminas foliares e relação folha:colmo para os pastos de milheto e papuã

\begin{tabular}{lcccc}
\hline Itens & Milheto & Papuã & $\mathrm{CV}, \%{ }^{1}$ & $\mathrm{P}^{2}$ \\
\hline Oferta de forragem & 15,3 & 13,2 & 19,5 & 0,2854 \\
Oferta de laminas foliares & 3,7 & 2,9 & 38,7 & 0,1257 \\
Relação folha/colmo & 0,5 & 0,4 & 44,6 & 0,0141 \\
\hline${ }^{1}$ Coeficiente de variação; ${ }^{2}$ Probabilidade pelo teste $\mathrm{F}$. & &
\end{tabular}

A relação folha/colmo (Tabela 2) diferiu entre espécies e dias de utilização da pastagem $(\mathrm{P}<0,05)$ e não se ajustou a nenhum modelo de regressão $(\mathrm{P}>0,05)$. O valor da relação folha/colmo representa apenas 50 e $40 \%$, respectivamente, para milheto e papuã da relação de 1,0, mencionada como ideal para forrageiras tropicais (Pinto et al., 1994). Nas datas de avaliação da ingestão, a relação folha/colmo foi de 0,49 e 0,31 ( $P>0,05)$, respectivamente, para os estádios vegetativo e reprodutivo dos pastos.

A oferta de lâminas foliares ajustou-se ao modelo linear de regressão $\left(\hat{Y}=6,26-0,04 \mathrm{dias} ; \mathrm{r}^{2}=0,54 ; \mathrm{CV}=38,4 \%\right.$; $\mathrm{P}=0,0001$ ), com valores de 5,5 a 1,7 kg de MS/ $100 \mathrm{~kg}$ de peso corporal, respectivamente, do início até o final da utilização da pastagem. Até 99 dias de pastejo, equivalente a 90,8\% do período total de utilização, o valor da oferta de lâminas foliares esteve acima do valor mencionado de ingestão de forragem para essa categoria de novilhas (NRC, 1996) (Tabela 2).

O ganho médio diário e a carga animal não foram influenciados pela interação entre espécies e períodos. O ganho médio diário, de $0,766 \mathrm{~kg}$, foi semelhante $(\mathrm{P}>0,05)$ entre as espécies de milheto e papuã. Houve efeito dos dias de utilização sobre o ganho médio diário dos animais, e esse ganho ajustou-se ao modelo de regressão quadrático, com valor máximo de ganho aos 53 dias de utilização da pastagem. O valor do ganho médio diário observado é igual ao ganho médio realizado por animais da mesma categoria, $0,766 \mathrm{~kg} / \mathrm{dia}$, em pastagens de clima temperado, aveia e azevém, em vários experimentos (Pötter et al., 2010). Na pastagem de papuã, em 73 dias de utilização, Martins et al. (2000) observaram ganho médio diário de $0,850 \mathrm{~kg} / \mathrm{dia}$ em novilhos. Montagner et al. (2008) observaram ganho médio diário de novilhas de corte em pastagem de milheto, que variaram de 0,5 a $0,8 \mathrm{~kg} / \mathrm{dia}$, que são condizentes com os ganhos observados neste trabalho.

A carga animal, com valor médio de $2.183,3 \mathrm{~kg} / \mathrm{ha}$ de peso corporal foi semelhante $(\mathrm{P}>0,05)$ entre as pastagens de milheto e papuã e não se alterou nos períodos $(\mathrm{P}>0,05)$. A reduzida oscilação no crescimento do pasto possibilitou manter constante a taxa de lotação, média de 6,9 novilhas/ha, durante todo o período de pastejo. Essa situação é bastante desejável para o manejo de pastagens anuais de verão, que costumam exigir maior taxa de lotação concentrada no início do ciclo (Montagner et al., 2008).

Não houve interação espécies $\times$ período para peso corporal e escore de condição corporal $(\mathrm{P}>0,05)$ e os valores foram semelhantes em milheto e papuã $(\mathrm{P}>0,05)$. O peso corporal e o escore de condição corporal se ajustaram ao modelo de regressão linear no transcorrer do ciclo dos pastos $(\mathrm{P}<0,05$; Figura 1). Em 109 dias de pastejo, houve um ganho de $85,5 \mathrm{~kg}$ de peso corporal e 0,53 ponto de escore de condição corporal. Os valores médios para peso e escore de condição corporal no final da utilização da pastagem foram, respectivamente, de $342,5 \mathrm{~kg}$ e 3,38 pontos. Esses valores comprovam que as novilhas, independentemente da espécie pastejada, estavam aptas para serem acasaladas aos 18 meses de idade, pois apresentavam peso correspondente a $76,1 \%$ do peso adulto, considerado de $450 \mathrm{~kg}$. Novilhas de corte, mestiças zebuínas, para serem consideradas aptas à reprodução, devem apresentar peso corporal correspondente a $67 \%$ do peso adulto (NRC, 1996). Todas as novilhas-teste atingiram o escore de condição corporal mínimo de 3 , que é o valor recomendado na entrada de novilhas de corte em reprodução.

Os tempos de pastejo, de ruminação e de ócio não sofreram influência da interação espécies $\times$ dias de
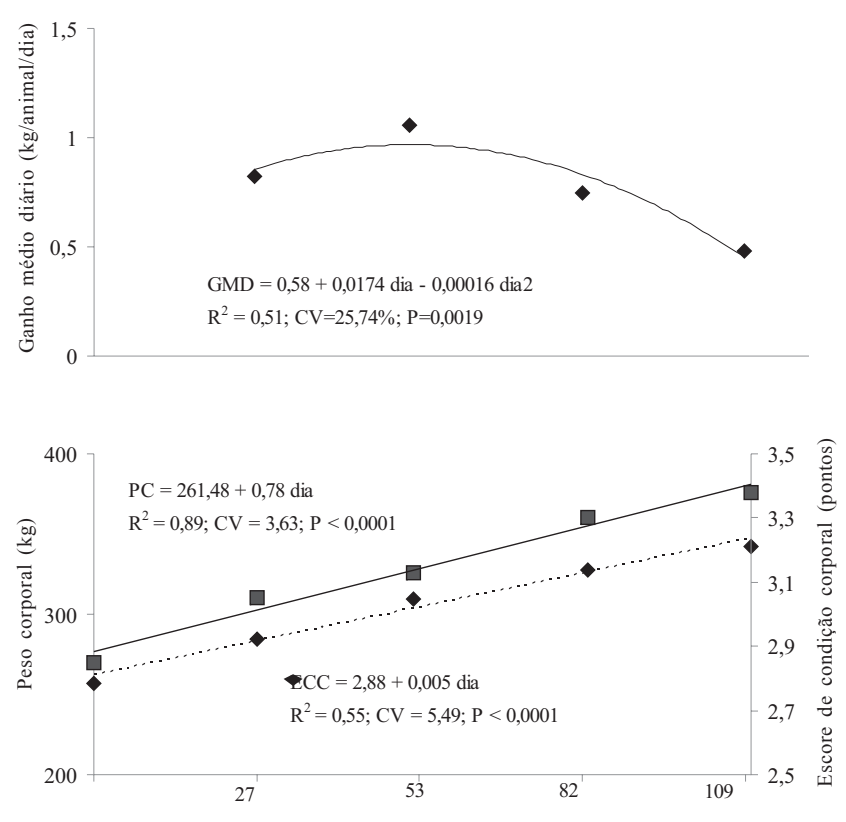

Dias após a utilização da pastagem

Figura 1 - Valores médios observados (pontos) e estimados (linha) de ganho médio diário, peso corporal e escore de condição corporal de novilhas de corte em pastagem de milheto e papuã. 
utilização $(\mathrm{P}>0,05)$ e foram semelhantes entre as pastagens de milheto e papuã $(\mathrm{P}>0,05)$. Os valores médios para tempo de pastejo, ruminação e ócio foram, respectivamente, de 611,$8 ; 443,9$ e 382,7 minutos/dia. O tempo de pastejo no início e final do período de utilização da pastagem $(642,7$ e 648,0 minutos/dia) foi superior ao período intermediário aos 82 dias $(568,9$ minutos/dia) $(\mathrm{P}<0,05)$, sem ajuste a nenhum modelo de regressão. Em pastagens de clima temperado, geralmente ocorre acréscimo linear no tempo de pastejo assim que a altura do dossel ou a massa de forragem diminuem (Hodgson, 1982), enquanto, em pastagens de clima tropical ou subtropical, essas relações não são tão evidentes (Sollemberg et al., 2005). Neste trabalho, houve decréscimo linear da altura e oferta de lâminas foliares no decorrer do ciclo dos pastos sem que o tempo de pastejo apresentasse a mesma tendência, pois as variáveis descritoras da pastagem e do pasto não estiveram correlacionadas $(\mathrm{P}>0,05)$ aos tempos de pastejo, ruminação e ócio.

O tempo de pastejo, que é a ligação entre a ingestão no curto prazo e o consumo diário de forragem (Hodgson et al., 1994) correlacionou-se de forma negativa com a temperatura máxima $(\mathrm{r}=-0,56 ; \mathrm{P}<0,01)$. O grupo genético das novilhas, predominantemente Angus, com pouca presença de sangue zebuíno, pode ter sido responsável pela resposta comportamental mais correlacionada a fatores ambientais do que com a estrutura do pasto. Isso porque animais com pelame vermelho e preto apresentam alta transmissão de radiação ultravioleta através da epiderme (Silva et al., 2001), reduzindo, em ambiente tropical, o tempo de pastejo em novilhas Angus, comparativamente a novilhas mestiças Angus $\times$ Brahman (Forbes et al., 1998). Como os fatores comportamentais não estão relacionados à estrutura do dossel, isso faz com que, para determinado conjunto de condições do pasto, não seja possível prever a ingestão em curto prazo (Cosgrove, 1997).

O tempo de ruminação diferiu entre períodos de avaliação $(\mathrm{P}<0,05)$ e os animais ruminaram por mais tempo na última em relação à terceira avaliação. $\mathrm{O}$ tempo de ruminação mostrou maior correlação, entre as variáveis meteorológicas, com a temperatura máxima $(\mathrm{r}=-0,57$; $\mathrm{P}<0,01)$. O tempo de ócio ajustou-se ao modelo de regressão quadrático $\left(\hat{\mathrm{Y}}=19,4+13,7\right.$ dias $\left.-0,1 \operatorname{dias}^{2} ; \mathrm{R}^{2}=0,60\right)$ e o máximo tempo de ócio foi aos 68 dias de uso da pastagem e ficou próximo ao ponto de máximo ganho médio diário. As condições estruturais do pasto não se correlacionaram $(\mathrm{P}>0,05)$ ao tempo dedicado ao descanso ou a interações sociais. Entre as variáveis de comportamento, o tempo de ócio foi a que apresentou maior correlação com variáveis meteorológicas temperatura máxima $(\mathrm{r}=0,72 ; \mathrm{P}<0,01)$ e temperatura média $(\mathrm{r}=0,69 ; \mathrm{P}<0,01)$.
As taxas de bocados (bocados/minuto) e de bocados por dia (bocados/dia) não foram afetados $(\mathrm{P}>0,05)$ pela interação espécies $\times$ períodos. A taxa de bocados não diferiu entre milheto e papuã $(\mathrm{P}>0,05)$ e os dias de utilização da pastagem ( $\mathrm{P}>0,05)$, com valor médio de 32,6 bocados/ minuto. Esse valor é inferior ao relatado por Stobbs (1974a) para a taxa de bocados em pastagens tropicais, de 70 a 80 bocados/minuto no início do pastejo e de $40-50$ bocados/ minuto no final. A taxa de bocado não se alterou com as mudanças registradas na oferta de lâminas foliares na altura do dossel e na relação folha/colmo e, provavelmente, não agiu como um mecanismo compensatório para manter a ingestão de forragem relativamente constante (Penning et al., 1991).

$\mathrm{O}$ número de bocados por dia não variou entre as espécies $(\mathrm{P}>0,05)$, mas apresentou diferenças entre os dias de utilização da pastagem $(\mathrm{P}<0,05)$ e não se ajustou $(\mathrm{P}>0,05)$ a nenhum modelo de regressão. A diferença de valores entre períodos está relacionada aos diferentes tempos de pastejo observados, pois a taxa de bocados foi constante no decorrer do ciclo.

Não houve diferença entre espécies e períodos $(\mathrm{P}>0,05)$ para o teor de proteína bruta da forragem, com valor médio de $16,7 \%$. Os teores de fibra em detergente e nutrientes digestíveis totais da forragem (Tabela 3) não apresentaram interação espécies $\times$ períodos e não diferiram entre espécies ou períodos $(\mathrm{P}>0,05)$. O valor médio do teor de nutrientes digestíveis totais foi de $54,8 \%$ e se correlacionou com o número de bocados diários $(\mathrm{r}=0,71$; $\mathrm{P}<0,01)$. Para o ganho individual realizado pelas novilhas, o teor de proteína bruta exigido é de $13,8 \%$ da MS da forragem (NRC, 1996) e o teor médio observado foi 17,8\% maior. $\mathrm{O}$ valor médio da fibra em detergente neutro foi de $61,84 \%$ e foi correlacionado com a oferta de lâminas $(\mathrm{r}=-0,65 ; \mathrm{P}<0,01)$.

A ingestão de MS e matéria orgânica ( $\mathrm{kg} / \mathrm{animal} / \mathrm{dia}) \mathrm{e}$ a ingestão de MS, como fração do peso corporal, não sofreram interação espécies $\times$ períodos $(\mathrm{P}>0,05)$ e foram semelhantes entre espécies ( $\mathrm{P}>0,05$; Tabela 3$)$. Os valores médios de ingestão foram de $7,41 \mathrm{~kg} /$ animal/dia de MS, $6,71 \mathrm{~kg} / \mathrm{animal} /$ dia de matéria orgânica e $24,9 \mathrm{~g} / \mathrm{kg}$ de peso corporal. Os valores de ingestão de MS e a ingestão de matéria orgânica (Tabela 4) foram maiores nos períodos correspondentes ao estádio reprodutivo. A ingestão de MS se correlacionou com o peso corporal das novilhas $(\mathrm{r}=-0,65 ; \mathrm{P}<0,01)$, com massa de forragem $(\mathrm{r}=0,62$; $\mathrm{P}<0,05)$ e com o escore de condição corporal $(\mathrm{r}=0,76$; $\mathrm{P}<0,01)$.

A ingestão de MS, em \% do peso corporal (Tabela 4), não diferiu entre períodos $(\mathrm{P}>0,05)$, e isso indica que a 
Tabela 3 - Componentes químicos, ingestão de MS e ingestão de componentes químicos da forragem, por novilhas em pastejo em pastagem de milheto e papuã

\begin{tabular}{|c|c|c|c|c|}
\hline Item & Milheto & Papuã & $\mathrm{CV}, \%^{1}$ & $\mathrm{P}^{2}$ \\
\hline Teor de matéria seca & 15,2 & 18,0 & 6,6 & 0,0203 \\
\hline Teor de proteína bruta & 16,4 & 16,1 & 12,0 & 0,7326 \\
\hline Teor de fibra em detergente neutro & 61,9 & 62,5 & 2,8 & 0,6112 \\
\hline Ingestão de matéria seca & 7,7 & 7,1 & 8,8 & 0,2628 \\
\hline Ingestão de matéria orgânica & 6,9 & 6,5 & 9,8 & 0,3244 \\
\hline Ingestão de fibra em detergente neutro & 5,2 & 5,0 & 11,2 & 0,1752 \\
\hline
\end{tabular}

${ }^{1}$ Coeficiente de variação; ${ }^{2}$ Probabilidade pelo teste F.

Tabela 4 - Componentes químicos, ingestão de MS e ingestão de componentes químicos da forragem, por novilhas em pastejo no estádio vegetativo e reprodutivo das pastagens de milheto e papuã

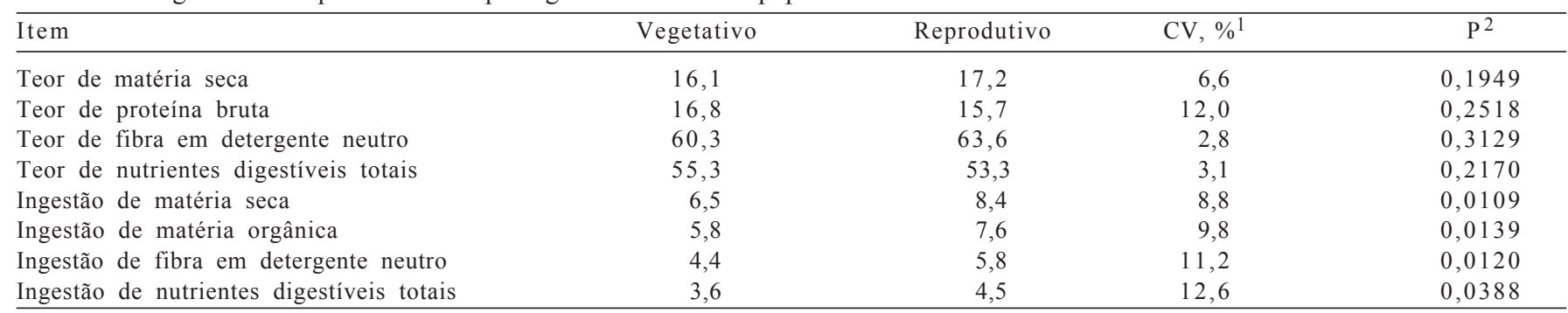

${ }^{1}$ Coeficiente de variação; ${ }^{2}$ Probabilidade pelo teste F.

mudança nas variáveis de ingestão, em kg/animal/dia, foi devida ao aumento do peso corporal e do volume ruminal das novilhas. Os valores médios da ingestão de MS em \% do peso corporal nos períodos correspondentes aos estádios vegetativo e reprodutivo foram, respectivamente, de 2,3 e 2,6\% (P>0,05).

Os animais ingeriram 7,41 e 4,03 kg/animal/dia de MS e nutrientes digestíveis totais, correspondentes a 2,49 e $1,33 \%$ do peso corporal, respectivamente. O teor de nutrientes digestíveis totais se correlacionou com a altura de dossel $(\mathrm{r}=0,75 ; \mathrm{P}<0,01)$, com tempo de ruminação $(\mathrm{r}=0,75 ; \mathrm{P}<0,01)$ e com o tempo de ócio $(\mathrm{r}=-0,74 ; \mathrm{P}<0,01)$.

Nos períodos correspondentes aos estádios vegetativo e reprodutivo, a ingestão de proteína bruta média foi 1,1 e $1,4 \mathrm{~kg} /$ animal/dia e não diferiu entre espécies e períodos $(\mathrm{P}>0,05)$.

A ingestão de fibra em detergente neutro não foi influenciada pela interação espécies $\times$ período e foi semelhante entre espécies $(\mathrm{P}>0,05)$, com valor médio de $5,08 \mathrm{~kg} / \mathrm{animal} / \mathrm{dia}$ (Tabela 4). Para valor semelhante de fibra em detergente neutro $(\mathrm{P}>0,05)$ entre os estádios, a ingestão de fibra em detergente neutro foi maior $(\mathrm{P}<0,05)$ no estádio reprodutivo, o que está relacionado ao aumento da capacidade de ingestão pelas novilhas. A ingestão de fibra em detergente neutro correlacionou-se com a relação folha/colmo $(\mathrm{r}=-0,69 ; \mathrm{P}<0,01)$, com oferta de lâminas foliares $(\mathrm{r}=-0,63 ; \mathrm{P}<0,05)$, com massa de forragem $(\mathrm{r}=0,60 ; \mathrm{P}<0,05)$ e com ganho médio diário $(\mathrm{r}=-0,73$; $\mathrm{P}<0,01)$. A maior ingestão de fibra em detergente neutro ocorreu no estádio reprodutivo, no qual a relação folha/ colmo foi menor, sugerindo que houve menor facilidade para a apreensão de folhas, que possuem menor teor de fibra em detergente neutro. Os valores médios de ingestão de fibra em detergente neutro nos estádios vegetativo e reprodutivo corresponderam, respectivamente, a 15,7 e $18,0 \mathrm{~g} / \mathrm{kg}$ de peso corporal de fibra em detergente neutro. Considerando esses valores, teriam existido limitações pelo volume ruminal, na ingestão de forragem, tanto em milheto quanto em papuã, pois essa ingestão ocorre a partir de $12,5 \mathrm{~g} / \mathrm{kg}$ de peso corporal de fibra em detergente neutro (Mertens, 1994). Os valores de ingestão observados, mesmo que próximos ao nível de $2,3 \%$ citado pelo NRC (1996), parecem ter limitado a ingestão de nutrientes das novilhas, pois nesse nível de ingestão, é recomendável oferecer dietas com $71 \%$ de nutrientes digestíveis totais, valor superior ao oferecido nas pastagens de milheto e papuã, com média de 54,8\%. O déficit energético, então, provavelmente, foi o fator limitante que não permitiu que as novilhas expressassem o seu potencial máximo de ganho.

Houve interação espécies $\times$ períodos $(\mathrm{P}<0,05)$ para a massa de bocado (g/bocado de MO) (Tabela 5), que, na pastagem de milheto, teve comportamento crescente $(\mathrm{P}<0,05)$ do estádio vegetativo para o reprodutivo em 
Tabela 5 - Massa de bocado no estádio vegetativo e reprodutivo e ingestão de MS em relação ao peso corporal em novilhas de corte em pastejo em milheto e papuã

\begin{tabular}{lccr}
\hline Itens & Vegetativo & Reprodutivo & CV, $\%^{1}$ \\
\hline Massa de bocado (milheto) & 0,263 & 0,403 & 2,1 \\
Massa de bocado (papuã) & 0,316 & 0,340 & 9,0 \\
Ingestão de matéria seca (milheto) & 2,6 & 8,9 & 0,3217 \\
Ingestão de matéria seca (papuã) & 2,4 & & 0,4341
\end{tabular}

${ }^{1}$ Coeficiente de variação; ${ }^{2}$ Probabilidade pelo teste F.

$53,2 \%$. Na pastagem de papuã, no entanto, essa tendência não foi observada $(\mathrm{P}>0,40)$ e a média foi de $0,33 \mathrm{~g} /$ bocado de matéria orgânica nos dois estádios. Os valores de massa de bocado para as espécies estudadas variaram na amplitude entre 0,40 e 0,26 g de matéria orgânica/bocado.

$\mathrm{O}$ fator de maior determinação sobre a ingestão de forragem foi a umidade relativa do ar $\left(\mathrm{r}^{2}=0,69\right)$, que prejudicou a ingestão, seguida da altura de dossel, que colaborou para a redução da ingestão $\left(\mathrm{r}^{2}=0,11\right.$; Tabela 6$)$.
Para ganho médio diário $\left(\mathrm{R}^{2}=0,74\right)$, o maior $\mathrm{r}^{2}$ parcial foi ligado à altura de dossel $\left(\mathrm{r}^{2}=0,25\right)$, que prejudicou o ganho. Entre as características de comportamento, o ganho médio diário foi reduzido pelo tempo de ruminação $\left(\mathrm{r}^{2}=0,23\right)$, que foi a variável mais importante, seguida pelo número de bocados diários $\left(\mathrm{r}^{2}=0,10\right)$. Na composição química da forragem, a variável de maior importância foi o teor de fibra em detergente neutro $\left(\mathrm{r}^{2}=0,05\right)($ Tabela 6$)$.

Tabela 6 - Equações de regressão múltipla para ingestão de matéria seca $(\mathrm{kg})$ e ganho médio diário $(\mathrm{kg})$ em novilhas de corte em pastagens de milheto e papuã

\begin{tabular}{llcccc}
\hline Variável & & Estimativa & $\mathrm{r}^{2}$ parcial & $\mathrm{R}^{2}$ total & \multicolumn{1}{c}{$\mathrm{P}$} \\
\hline Ingestão de MS & Intercepto & 26,28374 & - & - & - \\
& UMR & 0,07839 & 0,69 & 0,0008 & 0,0577 \\
& A T & $-0,05860$ & 0,11 & - & - \\
Ganho médio diário & Intercepto & 6,18105 & - & - & 0,0117 \\
& NBOC & $-0,00003$ & 0,10 & 0,16 & 0,0294 \\
& FDN & $-0,06688$ & 0,23 & 0,74 & 0,0122 \\
\hline
\end{tabular}

\section{Conclusões}

Pastagens de papuã possibilitam desempenho, comportamento ingestivo, ingestão de forragem e ingestão de nutrientes digestíveis totais semelhantes aos obtidos em pastagem de milheto. É possível utilizar áreas infestadas com papuã na produção de bovinos de corte.

\section{Referências}

ALLDEN, W.G.; WHITTAKER, A.M. The determinants of herbage intake by grazing sheep: the interrelationship of factors influencing herbage intake and availability. Australian Journal of Agricultural Research, v.21, p.755, 1970.

ASSOCIATION OF OFFICIAL ANALYTICAL CHEMISTS - AOAC. Official methods of analysis. 14.ed. Washington, 1984. $1141 \mathrm{p}$.

CARVALHO, P.C.F.; GENRO, T.C.M.; GONÇALVES, E.N. et al. A estrutura do pasto como conceito de manejo: reflexos sobre o consumo e a produtividade. In: REIS, R.A.; SIQUEIRA, G.R.; BERTIPAGLiA, L.M.A. (Eds.) Volumosos na produção de ruminantes. Jaboticabal: Funep, 2005. p.107-124.
COSGROVE, G.P. Grazing behaviour and forage intake. In: SIMPÓSIO INTERNACIONAL SOBRE PRODUÇÃO ANIMAL EM PASTEJo, 1997, Viçosa, MG. Anais... Viçosa, MG: Universidade Federal de Viçosa, 1997. p.59-80.

EMPRESA BRASILEIRA DE PESQUISA AGROPECUÁRIA EMBRAPA. Centro Nacional e Pesquisa em Solos. Sistema Brasileiro de classificação de solos. Brasilia: Embrapa-SPI; Rio de Janeiro: Embrapa-Solos, 2006. 306p.

EUCLIDES, V.P.B.; CARDOSO, E.G.; MACEDO, M.C.M. et al. Consumo voluntário de Brachiaria decumbens cv. Basilisk e Brachiaria brizantha cv. Marandu sob pastejo. Revista Brasileira de Zootecnia, v.29, p.2200-2208, 2000. (sup1. 2) FORBES, T.D.; ROUQUETTE JR, F.M.; HOLLOWAY, J.W Comparisons among Tuli-Brahman, and Angus-sired heifers: intake, digesta kinetics, and grazing behavior. Journal Animal Science, v.76, p.220-227, 1998.

FORBES, T.D.A. Researching the plant-animal interface: the investigation of ingestive behavior in grazing animals. Journal of Animal Science, v.66, p.2369-2379, 1988.

GENRO, T.C.M.; EUCLIDES, V.P.B.; MEDEIROS, S.R. Ingestão de matéria seca por ruminantes em pastejo. In: REUNIÃO ANUAL DA SOCIEDADE BRASILEIRA DE ZOOTECNIA, 41., 2004, Recife. Anais... Recife: 2004. (CD-ROM).

HERINGER, I.; CARVALHO, P.C.F. Ajuste da carga animal em experimentos de pastejo: uma nova proposta. Ciência Rural, v.32, n.4, p.675-679, 2002. 
HERINGER, I.; MOOJEN, E.L. Potencial produtivo, alterações da estrutura e qualidade da pastagem de milheto submetida a diferentes níveis de nitrogênio. Ciência Rural, v.31, n.2, p.875-882, 2002.

HODGSON, J.; CLARCK, D. A.; MITCHELL, R. J. Foraging behavior in grazing animals and its impact on plant communities. In: FAHEY, C.G. (Ed.) Forage quality, evaluation and utilization. Lincoln: American Society of Agronomy, 1994. p.769-827.

HODGSON, J. Ingestive behavior. In: LEAVER, J.D. (Ed.) Herbage intake handbook. Hurley: British Grassland Society, 1982. p. 113 .

JAMIESON, W.S.; HODGSON, J. The effect of daily herbage allowance and sward characteristics upon the ingestive behavior of calves under strip-grazing management. Grass and Forage Science, v.34, p.261-271, 1979.

KOZLOZKI, G.V.; FLORES, E.M.M.; MARTINS, A.F. Use of Chromium Oxide in digestibility studies: variations of the results as a function of the measurement method. Journal Science Food Agriculture, v.76, p.373-376, 1998.

KOMAREK, A.R. A fiber bag procedure for improved efficiency of fiber analyses. Jounal of Dairy Science, v.76, supl.(1), p.250, 1993.

LICITRA, G.; HERNANDEZ, T.M.; VAN SOEST, P.J. Standardization of procedures for nitrogen fractionation of ruminat feeds. Animal Feed Science Technology, v.57, p.347-358, 1996.

MARTINS, J.D.; RESTLE, J.; BARRETO, I.L. Produção animal em capim papuã (Brachiaria plantaginea (Link) Hitchc) submetido a níveis de nitrogênio. Ciência Rural, v.30, n.5, p.887-892, 2000.

MAYES, R.W.; LAMB, C.S.; COLGROVE, P.M. The use of dosed and herbage n-alkanes as marker for the determination of herbage intake. Journal Agricultural Science, v.107, p.161-170, 1996.

MERTENS, D.R. Regulation of forage intake. In: FAHEY, G.C. JR; COLlins, M.; MERTENS, D.R. et al. (Eds.). Forage quality evaluation and utilization. Madison: American Society of Agronomy, Crop Science of America; Soil Science of America, 1994. p.450-493.

MONTAGNER, D.B.; ROCH, A.M.G.; SANTOS, D.T. et al. Manejo da pastagem de milheto para recria novilhas de corte. Ciência Rural, v.38, n.8, p.2293-2299, 2008.

NATIONAL RESEARCH COUNCIL - NRC. Nutrient requirement of beef cattle. 7.ed. Washington: National Academy, 1996. $90 \mathrm{p}$.
NATIONAL RESEARCH COUNCIL - NRC. Nutrient requirement of dairy cattle. 7.ed. Washington: National Academy, 2001. $381 \mathrm{p}$.

PILAU A.; LOBATO, J.F.P. Manejo de novilhas prenhes aos 13/15 meses de idade em sistemas a pasto. Revista Brasileira de Zootecnia, v.37, n.7, p.1271-1279, 2008.

PINTO, J.C.; GOMIDE, J.A.; MAESTRI, M. et al. Crescimento de folhas de gramíneas forrageiras tropicais, cultivadas em vasos, com duas doses de nitrogênio. Revista Brasileira de Zootecnia, v.23, n.3, p.327-332, 1994.

POND, K.R.; ELLIS, W.C.; MATIS, J.H. et al. Passage of chromiummordanted and rare earth-labeled fiber: time of dosing kinetics. Journal Animal Science, v.67, n.4, p.1020-1028, 1989.

PENNING, P.D.; HOOPER, G.E.N. A evaluation of the use of short-term weight changes in sward characteristics under continuouds stoking. Grass and Forage Science, v.46, p.15-28, 1991.

PÖTTER, L.; ROCHA, M.G.; ROSO, D. et al. Suplementação com concentrado para novilhas de corte mantidas em pastagens cultivadas de estação fria. Revista Brasileira de Zootecnia, v.39, n.5, p.992-1001, 2010.

RESTLE, J.; ROSO, C.; AITA, V. et al. Produção animal em pastagem com gramíneas de estação quente. Revista Brasileira de Zootecnia, v.31, n.3, p.1491-1500, 2002.

ROBERTSON, J.B.; VAN SOEST, P.J. The detergent system of analysis. In: JAMES, W.P.T.; THEANDER, O. (Eds.) The analysis of dietary fibre in food. New York: Marcel Dkker, 1981. p.123-158.

ROMAN, J.; ROCHA, M.G.; GENRO, T.C.M. et al. Características produtivas e estruturais do milheto e sua relação com o ganho de peso de bezerras sob suplementação alimentar. Revista Brasileira de Zootecnia, v.37, n.2, p.205-211, 2008.

ROCHA, M.G.; SANTOS, D.T.; PILAU, A. et al. Desenvolvimento de novilhas de corte submetidas a diferentes sistemas alimentares. Revista Brasileira de Zootecnia, v.33, n.6, p.2123-2131, 2004 (supl. 2).

SILVA, R.G.; LA SCALA JUNIOR, N.; POCAY, P.L.B. Transmissão de radiação ultravioleta através do pelame e da epiderme de bovinos. Revista Brasileira Zootecnia, v.30, n.6, p.1939-1947, 2001.

SOLLENBERG, L.E; MOORE, J.E; ALLEN, V.G. et al. Reporting forage allowance in grazing experiments. Crop Science Society of America, v.45, p.896-900, 2005.

STATISTICAL ANALYSES SYSTEM - SAS. Statistical analysis user's guide. Version 8.2. Cary: SAS Institute, 2001. 1686p.

STOBBS, T.H. The effect of plant structure on the intake of tropical pastures. I. Variation in the bite size of grazing cattle. Australian Journal of Agricultural Research, v.24, n.6, p.809-819, 1973a. 